Андронова Ирина Владимировна

доктор экономических наук, профессор, профессор кафедры менеджмента в отраслях ТЭК Тюменского индустриального университета

Осиновская Ирина Владимировна

кандидат экономических наук, доцент, доцент кафедры менеджмента в отраслях ТЭК Тюменского индустриального университета

\section{ТЕХНОЛОГИЯ РАЗРАБОТКИ И ПРИНЯТИЯ УПРАВЛЕНЧЕСКИХ ИННОВАЦИОННЫХ РЕШЕНИЙ В НЕФТЕГАЗОВЫХ КОМПАНИЯХ}

\section{Аннотация:}

В статье дается системное представление о технологии разработки и принятия управленческих решений инновационного характера, имеющих многоуровневую структуру. Особое место отводится реализации форсайт-проектов, ориентированных на направления возможных технологических прорывов. Делается акцент на развитии инновационного потенциала компании, основой которого является персонал с инновационным складом мышления (инноваторы). Раскрываются основные требования, предъявляемые к инноваторам. Затрагивается вопрос о необходимости их специальной подготовки, возможно, в форме корпоративного обучения.

Ключевые слова:

инновационные решения, форсайт, алгоритм, персонал, инновационный потенциал, корпоративное обучение.

\section{Andronova Irina Vladimurovna}

D.Phil. in Economics, Professor, Fuel Energy Complex Management Department, Industrial University of Tyumen

\section{Osinovskaya Irina Vladimirovna}

PhD in Economics, Assistant Professor Fuel Energy Complex Management Department, Industrial University of Tyumen

\section{DEVELOPMENT \\ AND MANAGERIAL INNOVATIVE DECISION-MAKING TECHNOLOGY IN OIL AND GAS COMPANIES}

Summary

This article provides a systematic understanding of the development and managerial innovative decision-making technology having a multi-level structure. The implementation of the foresight projects aimed at possible technological breakthroughs plays the key role in the hierarchy of innovative solutions. The article focuses on the development of the company's innovative potential, which is based on the staff with an innovative way of thinking. It reveals the basic requirements for the innovators. The authors address the need for their special training that can be carried out in the form of corporate training.

Keywords.

innovative solutions, foresight, algorithm, staff, potential for innovation, corporate training.

Основой успешного развития нефтегазового бизнеса, и особенно его производственной составляющей, по-прежнему остаются инновационные технологии, которые обеспечивают значительные конкурентные преимущества компаниям, активно реализующим инновационные проекты во всех бизнес-сегментах: от геологоразведки до переработки и сбыта продукции. В условиях жесткой конкурентной борьбы нефтяные компании вынуждены рассматривать вопросы внедрения передовых инноваций не только технического характера, но и управленческого, заниматься активным продвижением управленческих инноваций во все функциональные подсистемы, и в первую очередь в подсистему управления персоналом.

По мнению Питера Друкера, одного из самых влиятельных теоретиков менеджмента XX в., главной движущей силой новой экономики являются инновации: «Каждой организации - и не только в сфере бизнеса - необходима одна стержневая компетенция: инновации» [1].

Стратегия внедрения инноваций во всех сферах деятельности функционирования социально-экономических систем становится основой развития нефтегазовой отрасли.

В выступлении президента Союза нефтегазопромышленников России Геннадия Шмаля на семинаре «Инновационные процессы в нефтегазовой промышленности» отмечено, что в России на науку тратится 0,86 \% ВВП, что значительно меньше, чем в передовых странах. Для сравнения показано, что затраты на НИОКР всех нефтяных российских компаний вместе с Газпромом составляют около 250 млн долл. в год. Для сопоставления, компания «Шелл» только в кризисном 2009 г. потратила на эти мероприятия более 1 млрд долл. По инновационному индексу и индексу технологической готовности среди 25 первых стран мира России нет [2].

В то же время в нефтегазодобывающей отрасли в настоящее время сложилась ситуация, когда добыча нефти с использованием старых технологий и подходов уже не может обеспечить компаниям необходимый уровень добычи, а добыча с активным использованием инноваций еще только находится на этапе зарождения. Инновационные подходы к добыче нефти будут основываться на внедрении принципиально новых технологий и техники в производственные процессы. 
Поступательное развитие нефтегазовой отрасли зависит от того, какие новые «прорывные» технологии и оборудование будут использоваться нефтяными компаниями, какие современные методы разработки трудноизвлекаемых запасов будут в распоряжении нефтяных компаний, какие инновационные технологии будут реализованы на всех этапах производственного цикла в различных операционных сегментах.

Таким образом, в нефртегазовой отрасли в большей степени будут преобладать процессные инновации, которые окажут существенное влияние не только на конечные результаты деятельности нефтяных компаний, но и на экономику страны в целом.

При ориентации на модернизацию без фундаментальной, отраслевой, вузовской, смежной науки осуществлять поступательное движение не представляется возможным. С учетом сложившейся ситуации развитие нефтяного бизнеса должно быть основано на интенсификации инновационных процессов, превращении их в фактор технологического и экономического роста. Это подтверждается и восприятием топ-менеджмента нефтегазовых компаний инновационной деятельности в качестве одного из ключевых фракторов успеха (рис. 1).

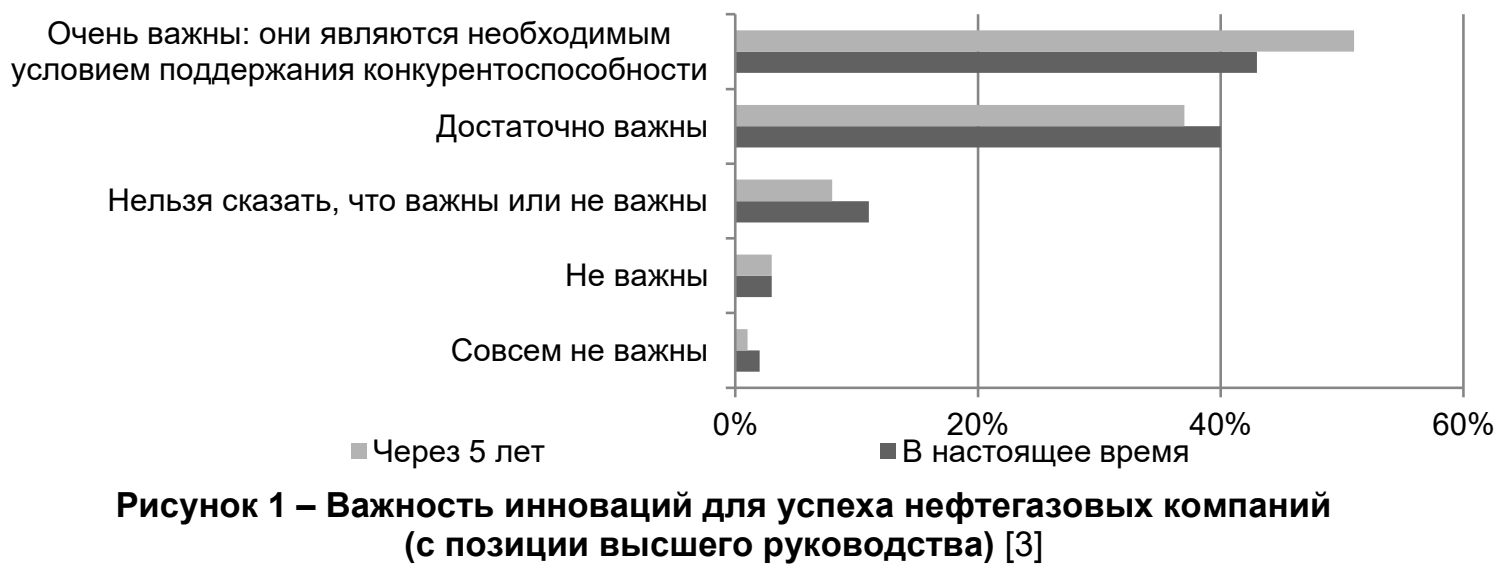

Все это обусловливает актуальность вопроса выработки технологии подготовки и обоснования управленческих решений во всех подсистемах деятельности нестегазовых компаний. Алгоритм разработки и реализации инновационных решений представлен на рисунке 2.

Вся система подготовки инновационных решений должна основываться на четко сформулированной инновационной стратегии нефтяной компании и вписываться в общекорпоративную стратегию. Процесс подготовки решений инновационного характера начинается с формирования актуализированного информационного поля относительно реализуемых и возможных к реализации инноваций во всех операционных сегментах компании. В первую очередь акцент делается на технологических инновациях, что обусловлено остротой проблем, связанных с ростом доли трудноизвлекаемых запасов, снижением коэффрициента извлечения нефтти и изменениями других важных технологических параметров каждого из направлений деятельности. Во вторую очередь изучаются возможности внедрения управленческих инноваций.

На данном этапе возможны так называемая «фотография» ситуации в компании на определенный момент времени и выбор обоснованного периода упреждения. Анализ сформированного информационного поля позволит выявить проблемные ситуации в каждом бизнес-сегменте и возможности их устранения с помощью внедрения инноваций.

Следующим шагом в подготовке инновационных решений идет разработка многоуровневой системы альтернативных вариантов решений. Первый уровень предполагает концентрацию решений относительно реализации инновационных форсайт-проектов, так называемый уровень «взгляд в будущее». Доля альтернативных решений, относящихся к данному уровню, будет относительно небольшая, но они будут достаточно значимыми для компании, так как в них заложена траектория долгосрочного ее развития и повышения инновационного потенциала.

Разработка альтернативных решений по реализации форсайт-проектов для нефтяных компаний прежде всего предполагает отбор стратегических направлений инновационного развития, а также выявление технологических прорывов, способных оказать существенное воздействие на развитие и увеличение ключевых показателей в различных операционных системах компании. Данный уровень решений фрормируется исключительно на основе методов экспертных оценок и обработке мнений высококвалифрицированных экспертов-аналитиков, прогнозистов. Обусловленность привлечения экспертов заложена в самой сущности альтернативных решений данного уровня, а именно, независимо от предполагаемого для внедрения операционного сегмента, решения будут основываться на технологиях, которые на данный момент еще не могут быть применены, а вся область практического их применения - это область будущих возможностей. 


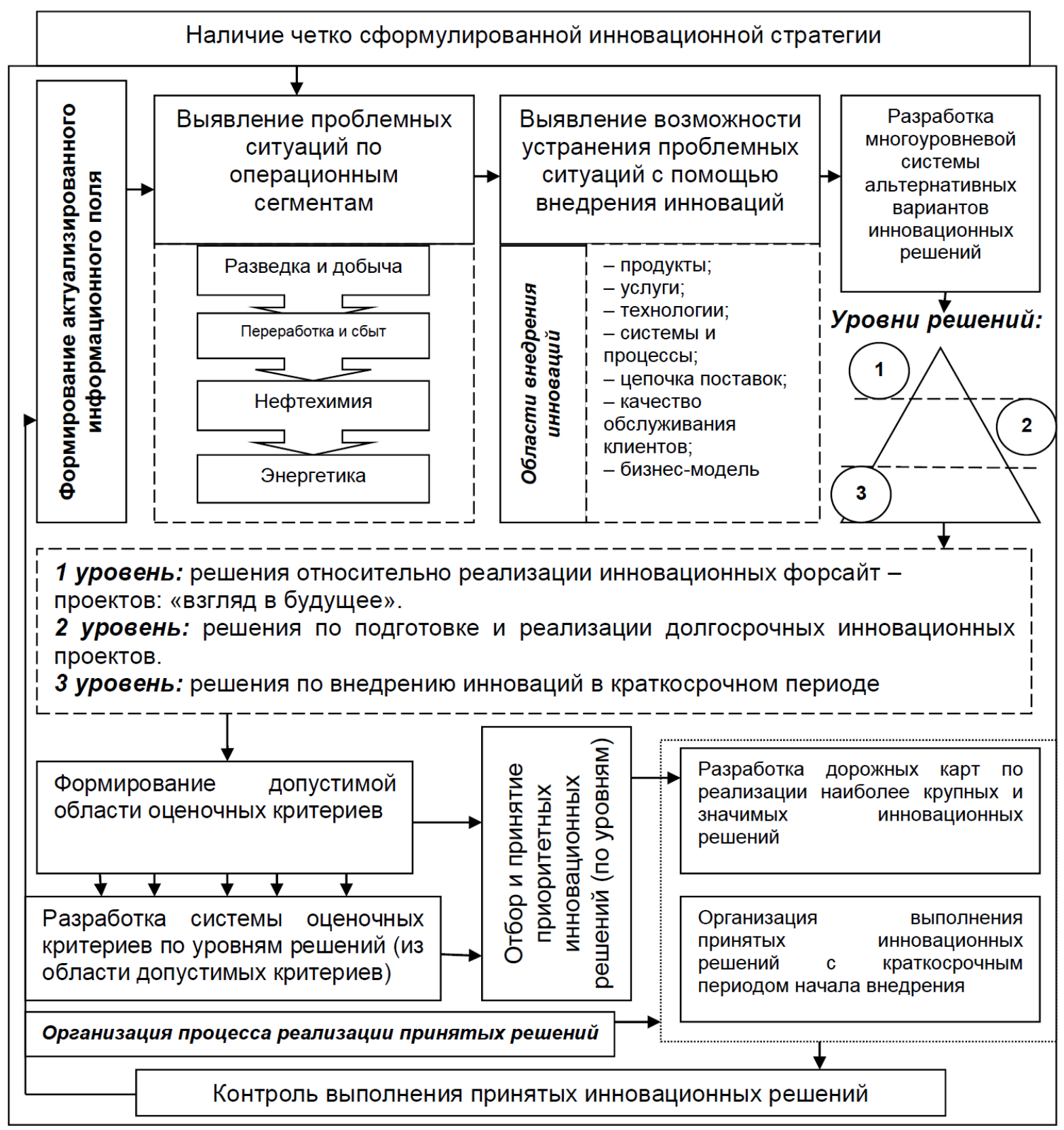

\section{Рисунок 2 - Алгоритм подготовки и реализации инновационных решений на уровне нефтегазодобывающих структур}

Второй уровень альтернативных решений будет охватывать возможность участия компании в реализации долгосрочных инновационных проектов. Доля данных решений будет естественно выше, чем на предыдущем уровне. На последнем уровне будут формироваться альтернативы относительно внедрения инноваций в краткосрочном периоде.

Роль экспертов будет достаточно высокой на каждом уровне разработки инновационных решений. Их участие необходимо как при построении дерева целей и соотнесении с ним альтернативных инновационных решений, так и на этапе их окончательного выбора, расстановки приоритетов и очередности реализации.

После того как разработана многоуровневая система альтернативных вариантов инновационных решений, формируется допустимая область оценочных критериев. Ее формирование может быть начато и в процессе подготовки альтернативных вариантов.

На основании сформированной системы оценочных критериев осуществляются отбор и принятие приоритетных инновационных решений (по уровням). Организация процесса реализации принятых решений предполагает два направления:

- разработку дорожных карт по реализации наиболее крупных и значимых инновационных решений; 
- разработку краткосрочных программ внедрения инновационных проектов.

Контроль выполнения принятых инновационных решений является завершающим этапом в алгоритме подготовки и реализации инновационных управленческих решений на уровне нефтегазодобывающих структур. Неудовлетворительные результаты, выявленные на этапе контроля, придают алгоритму циклический характер и предполагают возможность возврата на первый этап с целью корректировки принятых ранее решений и подготовки новых.

Эффрективная реализация инновационных управленческих решений в нефтегазовых компаниях невозможна без кадрового инновационного потенциала, основу которого составляют прежде всего талантливые, способные люди. Активизация инновационной деятельности в настоящее время невозможна без использования интеллектуального ресурса - высококвалифицированных специалистов и профессионалов-экспертов, обладающих набором уникальных компетенций, которые своим опытом, знаниями и нестандартным мышлением помогают находить решения сложных, нетривиальных производственных задач и участвовать в процессе создания новых технологий. Дальнейшее поступательное развитие бизнеса без интеллекта не представляется возможным.

Все это предопределяет необходимость повышения значимости и постановки особых задач в области подготовки талантливого, инновационно ориентированного персонала, то есть особой группы работников-инноваторов. Персонал, который можно отнести к данной группе, должен удовлетворять таким требованиям, как высокая самомотивация, развитое творческое воображение, способность к генерации идей и аналитической деятельности, оригинальность, креативность и широта мышления, энциклопедизм, логика, интуиция, умение работать в команде, развитый интеллект. Однако комплексной технологии массовой подготовки инноваторов пока не существует.

Для решения обозначенной задачи нефтяные компании могут пойти по пути расширения функций системы корпоративного обучения. Помимо стандартных составляющих, характерных для любой (в том числе и нетехнологичной) компании, функция корпоративного обучения и повышения квалификации персонала должна обладать двумя чрезвычайно важными взаимосвязанными составляющими:

- проведение опережающего обучения персонала для реализации инновационных проектов и научно-исследовательских работ нефтяной компании,

- развитие у персонала способности быстрого эффеективного поиска новых инженерно-технических решений.

Опережающее обучение создаст возможность минимизировать риски, будет способствовать успешной реализации инновационной стратегии и сможет вывести нефтяную компанию в лидеры по отдельному направлению технологического развития.

Таким образом, создание целостной системы подготовки и реализации инновационных управленческих решений на уровне нефтегазовых компаний позволит сформировать реальный механизм своевременного использования новшеств, что, в свою очередь, обеспечит нефтяным компаниям усиление конкурентных преимуществ, лидерских позиций по стратегическим и приоритетным направлениям и, как следствие, позволит осуществить переход от работ по обеспечению текущей производственной деятельности к созданию новых и совершенствованию применяемых технологий в области геологоразведки, разработки, добычи и повышения нефтеотдачи пластов.

\section{Ссылки:}

1. Друкер П.Ф. Информация, которая действительно нужна руководителю // Измерение результативности компании : пер. с англ. М., 2006.

2. Шмаль Г.И. Тезисы выступления на семинаре в ИМЭМО РАН «Инновационные процессы в нефтегазовой промышленности» [Электронный ресурc]. URL: http://www.imemo.ru/ru/conf/2013/12032013/SHM_12032013.pdf (дата обращения: 10.02.2016).

3. Инновации в нефтегазовом секторе [Электронный ресурc]. URL: http://www.pwc.ru/ru/energy-utilities-mining/publications/assets/innovation_survey2014.pdf (дата обращения: 17.12.2015).

\section{References}

Drucker, PF 2006, 'Information that the manager really needs', Izmereniye rezul'tativnosti kompanii, Moscow, (in Russian). Innovations in the oil and gas sector 2015, viewed 17 December $2015<$ http://www.pwc.ru/ru/energy-utilities-mining/publications/assets/innovation survey2014.pdf >, (in Russian).

Shmal, GI 2016, Theses of the speech at the seminar "Innovation processes in oil and gas industry" at the Institute of World Economy and International Relations of Russian Academy of Sciences, viewed 10 February 2016, <http://www.imemo.ru/ru/conf/2013/12032013/SHM_12032013.pdf>, (in Russian). 